\title{
Organisms as Persisters
}

\author{
Subrena E. Smith*
}

This paper addresses the question of what organisms are and therefore what kinds of biological entities qualify as organisms. For some time now, the concept of organismality has been eclipsed by the notion of individuality. Biological individuals are those systems that are units of selection. I develop a conception of organismality that does not rely on evolutionary considerations, but instead draws on development and ecology. On this account, organismality and individuality can come apart. Organisms, in my view, are as Godfrey-Smith puts it "essentially persisters." I argue that persistence is underpinned by differentiation, integration, development, and the constitutive embeddedness of organisms in their worlds. I examine two marginal cases, the Portuguese Man O' War and the honey bee colony, and show that both count as organisms in light of my analysis. Next, I examine the case of holobionts, hosts plus their microsymbionts, and argue that they can be counted as organisms even though they may not be biological individuals. Finally, I consider the question of whether other, less tightly integrated biological systems might also be treated as organisms.

\section{Keywords}

Organisms $\bullet$ Persistence $・$ Development $・$ Environment $\bullet$ Holobionts $\bullet$ Godfrey-Smith, Peter

\section{Introduction}

Some things are living and some are not. Under the heading "living things" come entities at various levels of biological organization. Some are called "organisms." However, the term "organism" does not pick out organismal entities uniformly — that is, among all the things that are considered to be whole living systems, some are regarded as indisputably organisms, and others are accorded only qualified organismic status. Perhaps this is because it is not clear why some biological systems should count as organisms and others should not.

This may, in part, explain why the concept of the organism has fallen out of fashion as a theoretical component of biology. But it is starting to make a comeback. As Huneman and Wolfe remark in an issue of History and Philosophy of the Life Sciences devoted to the organism question:

*Department of Philosophy, University of New Hampshire, Hamilton Smith Hall, 95 Main Street, Durham, NH, 03824, USA, subrena.smith@unh.edu

Received 9 June 2017; Revised 27 August 2017; Accepted 30 September 2017 doi:10.3998/ptb.6959004.0009.014

○ OPEN ACCESS - PTPBIO.ORG 
The concept of organism has been due for reconsideration for a number of years (with occasional calls for such reconsideration coming from historians, philosophers or theoretical biologists, e.g. Benson 1989, Labichler 2000). During the past fifteen-odd years a diverse body of work within the overall framework of the theory of evolution has called for renewed focus on the concept of organism, which had essentially disappeared with the rise of the modern synthesis in evolutionary theory, being replaced with the categories of gene and population, since evolution was defined as a process of change in allele frequencies within a population. (Huneman and Wolfe 2010, 147)

"Organism" has been overshadowed by the notion of "biological individuality." Confusingly, there is not consensus about the conceptual relation between organismality and biological individuality. Some seem to treat individuality and organismality as interchangeable (e.g., Clarke and Okasha 2013). Others understand the two concepts as separate and distinct (e.g., GodfreySmith 2013). Still others hold that the concept of the organism should be eliminated from scientific discourse, and replaced with that of the biological individual (e.g., Haber 2013, also Wilson 2000).

This displacement is bound up with another, more theoretical, emphasis. Philosophers tend to link individuality to evolutionary theory (Bouchard and Huneman 2013). That is, biological individuals are units of selection. Given the theoretical coupling of individuality and evolutionary considerations, it is not hard to see why the demotion of notion of the organism has coincided with the rise of an emphasis on individuality. The view that selection can occur at suborganismic and superorganismic levels is now a commonplace, so if selectability is what determines individuality, then there seems to be no reason to privilege organisms as paradigmatic individuals.

This paper is intended as a contribution to the case for organismality. The concept of the organism, I believe, is helpful in picking out a form of biological organization that is distinct from evolution-based conceptions of individuality and which draws instead on ecological and developmental biology. My approach to what I call the organism question-the question of what organisms are-is inspired by Peter Godfrey-Smith's distinction between biological individuals (bearers of fitness, units of selection) and organisms, which he describes as essentially persisters. Persistence, in this sense, is an ontogenetic rather than a phylogenetic notion. It pertains to individual organisms' spatiotemporal careers. Various persistence conditions follow from this. My account differs from Godfrey-Smith's because I foreground the conditions that are necessary for persistence. Organisms, in order to persist, must have well-differentiated and wellintegrated phenotypes that enable them to respond to the contingencies that they encounter. The integration of differentiated parts, which allows for phenotypic accommodation, provides the basis for the idea that organisms are in some sense whole systems (which is not to say that they are not entangled with their environments). Additionally, I present the view that organisms are not sharply distinguished from the worlds that they inhabit - that they are constitutively embedded in their worlds. Having set out this theoretical apparatus, I discuss two non-paradigmatic cases: the Portuguese Man O' War and the honey bee colony, and I show that both count as organisms by the criteria that I have set out. Next, I address the concept of holobiont systems. The holobiont concept has been criticized on the grounds that holobionts cannot be units of selection. I suggest that holobiotic systems may be fruitfully regarded as biological systems that are organisms but not biological individuals. I conclude by considering whether other, more loosely configured biological associations might be considered organisms (but not individuals), and suggest that, unlike individuality, which is categorical, organismality is incremental. A biological system can have more or less of it, and where one draws the line between organism and 
non-organism is more a function of one's explanatory project than a reflection of divisions in nature.

The analysis presented in this paper is an exercise in conceptual clarification rather than an empirical hypothesis. As such, it is intended as a contribution to the enrichment of the vocabulary and conceptual repertoire of theoretical biology rather than as a set of claims that form the basis for empirical predictions.

\section{Some Views about Organisms}

Whether presupposed or explicitly used, some notion of the organism is hard to avoid in the biological sciences (Pepper and Herron 2008; Huneman and Wolfe 2010), and is therefore significant for philosophers of biology (see for example Godfrey-Smith 2013; Wilson and Sober 1989; Wolfe 2016). But there is not consensus about what sorts of things ought to fall under the term.

In biology, the notion of organismality is used in various ways, depending on the particular explanatory interests of the investigator. For evolutionary developmental biologists such as West-Eberhard (2003), the organism is at the center of biological inquiry. In her view, it is the whole-organismic perspective, rather than the gene-centric perspective, that best illuminates the emergence of novel phenotypes and speciation events. For some evolutionary behavioral ecologists (for example, Westneat and Fox 2010), the organism is treated as the locus of behavior.

Although the question of what organisms are (i.e., what distinguishes them from other kinds of biological systems) often remains unaddressed in the literature, this is not always the case. For instance, Wilson and Sober (1989) propose that it is their "exquisite functional organization" (3) that secures some biological systems' status as organisms; they are entities with finely tuned functionally discrete parts resulting from the operation of natural selection. Others (such as Torres and Trainor 2008) conceive of organisms as bounded individuals with defined internal and external parts that have the capacity to distinguish between self and non-self. Still others (e.g., Turner 2000) take the organism to be a physiologically functional whole. Pradeu (2010) characterizes organisms immunologically, writing that "an organism is a functionally integrated whole, made up of heterogeneous constituents that are locally interconnected by strong biochemical interactions and controlled by systemic immune interactions" (258). Other criteria mentioned or discussed in the literature include indivisibility, contiguity, development from a single cell, membership in a single lineage, genetic uniformity, cotransmission, no partner change, and germ-soma separation (Santerlices 1999; Wilson 1999; Pepper and Herron 2008). Queller and Strassman (2009) argue that any biological system that can be characterized as possessing high levels of cooperation and low levels of conflict should count as an organism. For Godfrey-Smith (2013), organisms are functional metabolic units with parts that work to maintain the whole, and he does not require that all organisms belong to reproductive lineages.

These views of the organism have different emphases, but all are concerned with a certain sort of focal entity - entities said to exist at a certain rank of biological organization. The various conceptions do not exclude one another. An immunological focus need not be incompatible with a focus on behavior or physiology. For any of these views one might ask whether the feature that has been singled out specifies what it is that constitutes the organism, or whether it is a consequence of or a prerequisite for organismality. But these views do contradict one another if they purport to explain what organisms are essentially. So, for example, the claim that immunological unity is what makes a biological system an organism is not compatible with the claim that some other feature is what makes a biological system an organism. 
Peter Godfrey-Smith views organisms as things that persist; he says that "organisms are essentially persisters" $(2013,25)$. This conception of the organism is central to the picture that I will develop here. I think that his view is useful, but I think that more is needed. If organisms are essentially persisters, then to understand what this comes to, it is necessary to examine the general conditions for their persistence. By taking persistence as the explanatory basis for what organisms are, one can then enquire into those factors that facilitate persistence and hence organismality.

\section{Kinds of Organisms}

Different kinds of living systems are considered to be organisms. There are paradigmatic examples: whole, individual, living systems such as rats, fungi, maple trees, human beings, and sea bass. But how about highly integrated groups of living things, such as eusocial insect colonies? Should the group, considered as a collective entity, be regarded as having organismic status, or should such an ascription be restricted to the individuals that comprise the group? Opinions about which way to go are divided (Gardner and Grafen 2009). Some invoke an exclusion principle that if something is an organism than organisms cannot be its parts, while others demure (see Godfrey-Smith 2013). There are also composite candidate organisms to consider. Lichens are composites, formed from partnerships between cyanobacteria or algae and fungi, functioning as a single, stable unit. Is an "individual" lichen one organism, or several organisms, or both? All eukaryotic organisms - that is, all organisms apart from archaea and bacteria-possess mitochondria containing mitochondrial DNA, which is distinct from the DNA contained within the cell nucleus. Perhaps, therefore, we should consider all eukaryotes-including ourselves-as composites as well. There are many other examples (see, for instance, Wilson 1975).

An additional reason to consider many other organisms, including ourselves, as composites is the possession of a microbiome. Lynn Margulis (Margulis and Fester 1991) coined the term bolobiont to characterize composites of host systems and their micro-symbionts-a "compound of recognizable bionts" (3). In our own case, we depend for our existence on the one thousand or so varieties of bacteria that reside in our gut, but there are many other examples of such adaptive partnerships, such as the squid-Vibrio relationship:

Hawaiian bobtail squid (Euprymna scolopes) takes in a small number of bacteria of a certain kind (Vibrio fischeri) when it is very young. These bacteria grow into colonies within specialized "crypts" inside the squid, which form part of the squid's "light organ." No other bacteria can colonize these crypts. The organ lights up in a way that provides camouflage from predators watching from below, as it prevents the squid from casting a shadow. This shadow would be cast by moonlight-the squid hunts at night. At the dawn of each day, most of the bacteria are expelled, and the colony regrows from the remainder while the squid hides on the sea floor (Godfrey-Smith 2013, 29).

If we are willing to countenance such mutually dependent partnerships as organisms, why not extend the principle further? Must organismality end at a paradigmatic individual's skin? There have been compelling arguments that structures animals build should be considered extensions of their phenotype, and thus a part of the organism (Dawkins 1982; Turner 2002). Perhaps the boundaries of the organism can be pushed out further still, dissolving any absolute line of demarcation between organism and ecosystem. A tapeworm plus the gastrointestinal tract of the cow in which it lives is a living system. The cow plus the pasture on which it grazes is a 
living system too. Does cow plus tapeworm plus cow's microbiome plus pasture (with its many, many biota) add up to a macro-organism? If not, why not?

Some systems are sometimes treated as "sort of" organisms because they do not fully conform to conventional notions of what organisms are. If being an organism is something absolute (such that an entity either is one or isn't one), then these marginal cases might be understood as entities that resemble organisms in certain respects, but are not really organisms. Alternatively, one might think of organismality as a property that a biological system might have to a greater or lesser degree (e.g., Godfrey-Smith 2013; Queller and Strassmann 2009), and conclude that the marginal cases are just less organismic than the paradigmatic ones.

Both of these approaches appear to rely on a common inferential strategy. It begins with the notion that certain biological systems are unproblematically organisms while others are organisms only to the extent that they approximate, in some respect or respects, the allegedly paradigmatic examples. From this perspective, insofar as there are genuine questions to be asked about what living systems count as organisms, these questions concern the candidates that qualify as organisms only to the extent that they approximate the paradigmatic cases. But one might ask why these, and not others, have this privileged status? Why not (for example) treat the Portuguese Man O' War or the honey bee colony as paradigmatic and rats and humans as non-paradigmatic?

The use of paradigmatic cases as a benchmark for organismality seems rooted in commonsense ideas about what things count as organisms (that paradigm cases are paradigm cases is a presupposition rather than a discovery). An alternative method-one that I favor-is to start with some view of what organismality is and then investigate which biological systems satisfy it. If we begin with a conception of the property of organismality, and then determine what sorts of living systems satisfy this conception, rather than beginning with what we take to be paradigmatic organisms, and then determine what kinds of organisms approximate the uncontroversial cases, an answer to the question of whether a given biological system is an organism might or might not converge with commonsense assumptions.

However, I do not think that one can free oneself entirely from folk presuppositions when thinking about the organism question. So, it seems inevitable that one's point of departure will be paradigmatic cases and that one's initial assumptions about what organismality amounts to will be based on them.

What is key, then, is a decision about what attributes of paradigmatic organisms one will take as definitive of organismality. In order for the notion of the organism to have pragmatic utility, it must not be too specific (such that, for example only the members of certain taxa count as organisms) nor too general (at the extreme, so that all living systems count as organisms). Settling on a conception of organismality, then, requires one to find an optimum somewhere between these two extremes and appropriate to the explanatory projects at hand. For example, if one's goal is to say something about biological variability, then the definition of what an organism is might be different than is the case if the goal is to say something about development, or if one wishes to offer an origin explanation for some trait or phenomenon. Or one might think that a pluralistic approach might be the most appropriate way to go forward, since it might accommodate better the standard boundaries between kinds of systems. Unless of course, that is, one can configure a view that covers paradigmatic cases as well as non-paradigmatic cases, and which is appropriate to a broad range of kinds of explanatory projects.

In the final analysis, it seems that one needs to lean on commonsense sensibilities in order to move beyond them, and one should not delude oneself into thinking that one can, through some objective procedure, arrive at a conclusion about what organisms really are in a way that is wholly independent of one's explanatory interests. 


\section{Theoretical Desiderata}

The conception of organismality that I shall propose is one that satisfies four desiderata that I think any acceptable account of organismality should satisfy. (My account of organismality does not uniquely satisfy them.)

First, I want a conception that highlights that organisms are the sorts of things that persist, and that foregrounds the conditions that are necessary to secure their persistence. Second, I want a conception of organismality that accords with our best scientific understanding of the ontogenesis and persistence conditions of biological systems. Third, I want a conception of organismality that is ecological: one that does not ignore that, whatever organisms are, they are inevitably organisms-in-the-world. Fourth, I want a conception of organismality that does not rule out non-standard, counter-intuitive cases (so as not to stay entirely within the confines of commonsense assumptions about organismality). 1

\section{Persistence and Its Contexts}

I begin with a very general picture. Peter Godfrey-Smith has the view that "organisms are essentially persisters" $(2013,25)$. Whole biological systems, of the requisite sort, are persisters. This would appear to be a necessary assumption, but to say that organisms persist is to say very little about them and does not distinguish organisms from parts of organisms or ecosystems. Godfrey-Smith adds to the picture that organisms are "systems that use energy to resist the forces of decay and [only contingently], things that reproduce" $(2013,25)$. I take this to mean that organisms are units of living matter that are organized in such a way as to keep themselves going. It is the organization of those things that are organisms, then, that is a necessary condition for their persisting (although less than a sufficient one). More specifically, the sort of organization that is required is the differentiation of the phenotype into parts that serve particular functions, and the integration of those parts so that the functions that they serve contribute to the persistence of the whole. This functional organization buffers it against changes in its material conditions and enables it to respond to environmental contingencies in a coordinated manner (the "exquisite functional organization" cited by Wilson and Sober 1989; see also Walsh 2014). Further, because phenotypic differentiation and integration come about through developmental processes, it must be the case that those systems that count as organisms are systems that develop. These developmental processes involve an ongoing, dynamic, construction and reconstruction of individuals by sub-organismic, non-organismic, and other-organismic factors. Call these "contexts for development."

Phenotypes are modified throughout life-trajectories, and those modifications contribute to further modifications. Because persistence requires development, if organisms are "essentially" persisters, then to understand what organismality comes to, one needs to approach it from the standpoint of development, conceived of as involving the wide array of factors that make and sustain organisms. In calling these contexts, I mean to make it explicit that there are factors that are external to organisms' surface membranes that are constitutive of their status as organisms, and wish to emphasize that environments are not optional for the construction and persistence of organisms. It is not just what is inside of them that makes organisms what they are: an external world is a necessary condition for the development of any kind of living system.

Phenotypic plasticity is an important component of the contexts for development. ${ }^{2}$ It is

\footnotetext{
${ }^{1}$ For example, the conception set out in this paper might suggest that the cells composing multicellular organisms are themselves organisms.

${ }^{2}$ In the biological literature, plasticity (and its sibling concept canalization) is most often discussed
} 
"the ability of an organism to react to an environmental input with a change of form, state, movement, or rate of activity" (West-Eberhardt 2003, 34). The aspect of phenotypic plasticity most pertinent to the present discussion is phenotypic accommodation: the capacity of certain biological systems (those that are organisms) to respond as a whole to environmental contingencies which threaten or promote their persistence. Phenotypic accommodation is made possible by the fact that organisms function as integrated, cohesive wholes. Accepting that organisms are cohesive wholes does not preclude (nor does it challenge) the view that whole systems can have as parts other whole systems (e.g., lichens). Some systems require other kinds of systems in order that they can be persisters, and so, insofar as they are persisters, they are so by means of the systems with which they are associated. While I select whole living systems for consideration of organismality, I do not thereby diminish the significance of the intermingling of kinds of whole living systems into greater wholes which, because they are entangled, are also persisters. That is, any suitably integrated collection of whole living systems can be considered a persisting system, or one can choose any member of the collective as the focal system. The scale at which organismality is addressed may depend on the sorts of questions that one asks.

\section{Constitutive Embeddedness}

It is misleading to address development independently of the "environmental" contexts for development, but, even among some of the most sophisticated biological thinkers, one finds views that are tilted toward ignoring the reciprocal interplay between organisms and environments. (See, for example, Waddington's epigenetic landscape, which, as West-Eberhard [2003] observes, is static; see also Walsh 2014).

It is clear that very many contingent factors, both internal and external, need to be taken into account for an exhaustive treatment of development. However, it is often the case that factors that are internal to the organism are explanatorily privileged over "external" ones. Parts of the organism are given causal priority over causally significant factors that are not parts of the organism (narrowly construed). These include both resources lying outside the surface membrane that are characterized as parts of the organism's environment. Additionally, there are components existing beneath its surface membrane (symbionts), whose role in shaping them is often neglected, regarded as epiphenomenal or at least of negligible significance (Laubichler 2010; Lewontin 1991; Kitcher 2001).

Typically, organisms are understood as products of the relation between internal parts and processes and the environment, which is taken to be something that is separate and distinct from them. But this bifurcation of the world into organism and environment is misleading. Organisms presuppose environments. They are two sides of the same coin. They are of course conceptually distinguishable, but they are not in fact separable (by analogy, one can conceptually distinguish the "head" side of the coin from its "tail" side, even though these are not physically separable).

It is common to think of organism-environment relations causally, in interactionist terms, but less common to think of those relations constitutively. But one cannot in fact disengage organisms from their environments. Organisms are constitutively embedded in their worlds. They are organisms-in-the-world rather than just organisms in the world. This principle means having a commitment to the inseparability of organisms and environments, both internal and external,

in relation to evolution; more specifically, these discussions are mostly concerned with the degree to which plasticity contributes to or retards evolution (West-Eberhard 1989, Sultan 1992, Stearns 1983). Although not irrelevant to the organism question, such evolutionary considerations are not my focus here.

๑ OPEN ACCESS - PTPBIO.ORG 
as well as to a commitment to theorizing about them as beings that are inseparable from their worlds.

The developing organism is perpetually coming-into-being, and its coming-into-being involves its being folded into its world. Consider the folding of beaten egg whites into flour, sugar, and butter. The action of folding-in removes the separateness of the ingredients. Even though we can still conceive of the constituents as separate-egg whites, flour, sugar, and butter-we cannot extract them from the batter. When we combine the resources that form a cake batter we are apt to think of the batter rather than of the elements of the mixture, while also recognizing that the individual elements are constitutively necessary for the mixture. Likewise, the biological systems that we call "organisms" are inseparable from their contexts, even though one might treat them as distinct when engaging in certain sorts of explanatory projects, but it is not the case that organisms "fit" into pre-configured environments. Rather, as Lewontin (1986) has observed "the environments of organisms are made by the organisms themselves as a consequence of their own life activities" (280).

Walsh (2014) has expanded on Lewontin's insight, and explored what it means to say that organisms are entangled with their worlds, using the metaphor of the affordance landscape. On the traditional view of evolutionary change, organisms adapt to the world into which they are thrown. According to that picture, the environment provides a sort of template to which successful organisms conform. Members of a population either conform to the adaptive demands of the world in which they find themselves or they disappear. Successful organisms are described as occupying a pre-existing niche which, like a niche in which a statue is placed, is completely independent of its occupant. This is a picture that represents organisms as essentially passive systems - blank slates upon which the environment impresses itself. Walsh argues that this way of picturing the organism/world relation misrepresents it. He argues that organisms live in a world of affordances - opportunities for action. What counts as an affordance for an organism of a certain kind, that is, what counts as part of the environment for that organism, is dependent on the nature of the organism itself.

Affordances are not 'autonomous' from organisms, nor is there an asymmetric dependence of organisms on affordances. There is a reciprocity between organisms and affordances that does not hold between organisms and their niches and environments. What a feature of an environment affords an organism depends (in part) upon the organism's capacities, and the capacities of the organism depend (in part) on the features of the environment. Organisms and their affordances are co-constituting and 'commingled.' (Walsh 2014, 222)

The conceptual bifurcation of the world into organism and environment creates a tension that is only overcome by reasserting the constitutive embeddedness of organisms in their worlds. The focal entity - the persisting region of biological matter about which one is concerned-is always embedded in a context as it goes along living. The constitutive embeddedness of organisms in their worlds suggests that the line drawn between "organism" and "environment" is, although sometimes conceptually useful, metaphysically misleading.

\section{Two Cluster Cases}

I am now going to use two examples of non-paradigmatic cases to fill out the analysis. These cases-the Portuguese Man O' War and honey bee colony_satisfy the conditions for being

\footnotetext{
3"Organisms are adaptive precisely because their developmental capacities constitute a complex, interactive, 'commingled' system of organism and environment" (Walsh 2012, 107).
}

๑ OPEN ACCESS - PTPBIO.ORG 
organisms that I have set out.

The Portuguese Man O' War belongs to the order of organisms known as Siphonophores. Most of the approximately three hundred species belonging to this taxon, including the Man O' War, are colonial (Wilson 1975). Each individual consists of organizations of individual structures called "polyps," all of which are genetically identical and bud from a single founding polyp, which is produced from a fertilized egg. Each polyp is a zooid-that is, an animal-like individual with highly specialized functions. The Portuguese Man O' War is made up of four kinds of zooids. These are the pneumatophore, a gas (mostly carbon monoxide)-filled structure, which functions as a sail to catch the wind, the dactylzooids or tentacles, which are covered with venomous structures and are used for predation and defense, the gastrozooids, which digest prey that is trapped by the tentacles, and the gonozooids, or reproductive structures (Pechenik 2005; Dunn and Wagner 2006).

The zooids are specialized to such a degree that they cannot perform one another's functions, and they are so highly integrated and interdependent that they cannot survive independently of one another. Consider nutrition. The gonozoids, dactylzoids, and pneumataphore all depend on the gastrozoids to digest prey and provide them with nutrition. The gastrozoids depend on the datylzoids to capture and draw the prey up into their mouths. Because the Portuguese Man O' War cannot pursue its prey, but is dependent on wind (and currents) to move it through the water, where it drags its long tentacles like a floating net to catch prey, all of the zooids are partially dependent on the pneumataphore for their continued survival (Purcell 1989).

Is the Portuguese Man O' War a colony or a single organism? As Sterelny and Griffiths remark, Siphonophora like the Portuguese Man O' War "are so integrated that it is hard to say whether they consist of many cooperating organisms or a single organism" (1999, 24). And Wilson $(1975,383)$ states that "The dilemma can be restated as follows: At what point does a society become so nearly perfect that it is no longer a society? On what basis do we distinguish the extremely modified zooid of an invertebrate colony from the organ of a metazoan animal?" He concludes that Siphonophora "are both organisms and colonies" (384).

Although the case of the Portuguese Man O' War can pull one's intuitions in different directions, on my account it is clearly an organism. The Man O' War is a persister, and its persistence is secured by its having developed a differentiated phenotype (consisting of the zooids) that are highly functionally integrated, and which allow it to make use of the environment in which it is entangled.

Honey bees are eusocial insects that exist in colonies that are sometimes described as "superorganisms" (e.g., Hölldobler and Wilson 2009; Tautz 2008; Gillooly, Hou, and Caspari 2010) —although not without controversy. ${ }^{-4}$ Just as cells make and maintain the integrity of multicellular animals, each individual bee in a colony works to carry out colony-level tasks, which jointly result in the persistence of the colony. Among the tasks that are vital for the colony are thermoregulation, the exchange of air in and out of the hive, and the reproduction of new honey bees.

Honey bees, considered as individuals, are ectotherms, but the colony functions as an endothermic system that maintains a temperature at around ninety-three degrees Fahrenheit. When the temperature in the hive drops below the optimum, worker bees group around the brood nest and vibrate their wings producing heat from their thoracic muscles to bring the temperature back to its optimum (Seeley 1985; Stabentheiner, Kovac, and Brodschneider 2010). They also cool the hive when it exceeds the optimum temperature, by spreading out, fanning, evaporating water, or as a last resort evacuating the hive. Because hives are usually enclosed in trees and

\footnotetext{
${ }^{4}$ There are two main approaches to superorganismality: the selection approach and the similarity approach. See Hamilton et al. (2009) and Haber (2013). See also Okasha (2011) and Martens (2010).
} 
other places where airflow is restricted, worker bees ensure adequate air flow by fanning into and out of the entrance of the hive, causing the hive as a whole to "inhale" and "exhale" air (Seeley 1985). Honey bee reproduction does not depend on the queen alone, but involves a complex organization of activities on the part of the whole hive. Here is a description of the reproductive process:

The development of an individual honey bee does not differ much from that of any other holometabolic insect in principle, yet there are dramatic biotic constraints which govern the development of a honey bee. Most evident is the developmental pathway from egg to adult which can only occur in the presence of large numbers of other bees. The large body of workers is instrumental for brood rearing. They provide the combs where the queen deposits the eggs. They feed and foster the larvae and maintain the correct temperature for brood development. They also provide a nest site which is of crucial importance for temperature control and protection of the stores and the brood against predators. Thus, the successful completion of the above developmental cycle depends intricately on the presence of an intact colony comprised of a nest cavity, combs and a large number of other bees (Moritz and Fuchs 1998, 8).

Of note is that the whole colony has a life cycle: it begins with a single queen, grows, and eventually reproduces. When the hive reaches maximum capacity, more than half of the worker bees and the queen leave the hive to find a new one, and the remaining workers and the new queen (or queen-to-be cells) then reconstitute the hive (Seeley 1985).

Honey bee systems, too, are often treated as cases of marginal organismality because they lack the sort of integration that an individual animal is said to have. ("Superorganisms" are often treated as organisms only analogically). Any particular honey bee is clearly an individual organism, but to understand some things about honey bees, one needs to treat their colonies as whole organisms too. The worker bees are not differentiated in the sense of consisting of subgroups each of which performs some fixed function or set of functions, and they are therefore not integrated in the same way that metazoan cells are. But differentiation and integration can be realized in more than one way. In the case of the honey bee colony, the differentiation among worker bees is realized by their ability to flexibly adopt diverse functional roles as the circumstances demand (for example, foraging, repairing, and fanning the hive), and the integration of these differentiated parts accounts for the persistence of the hive.

\section{Holobionts and Their Implications}

I have shown that two ostensibly marginal cases, the Portuguese Man O' War and the honey bee colony, satisfy the criteria for organismality set out in my analysis. However, a critic of my position might justifiably assert that these two examples might just as well be considered biological individuals, and therefore that the utility of the organism concept has not yet been demonstrated. It is therefore important to locate an example of a biological system that is not an individual, in the technical sense, but which is nonetheless an organism. One such example is the holobiont.

As I have mentioned above, the term "holobiont" was introduced by Margulis (1991) to denote the symbiotic associations between individuals of different taxa over significant segments of their life cycles. These consist of a macrobiotic "host" and the many taxa of microbes that live in and on it. Corresponding to the holobiont is the hologenome- the combined genomes of the macrobiotic "host" and its various symbionts. So, "complex multicellular eukaryotes are 
not and have never been autonomous organisms, but rather are biological units organized from numerous microbial symbionts and their genomes" (Bordenstein and Theis 2015). In light of this, there is something odd about referring to holobionts as associations of a host and its symbionts, because there are no symbiont-free hosts. The symbiont populations do not just come along for the ride. They are vital for the persistence of the system, and are increasingly shown to have significant effects on the macrobial phenotype (e.g., Leitão-Gonçalves et al. 2017). That is to say, for any multicellular system that persists, it does so, in part, because of its holobiotic structure. What symbionts are nested in the association, how the symbionts interact with other symbionts and with their host systems, are all key.

The existence of holobiotic systems suggests that organismality and individuality come apart. Recall that on the standard view of individuality, a biological item is an individual if it is apt for selection. Selection requires reproduction with fidelity, but "holobionts ... exhibit determinate lineages among their parts (the analog of gene lineages in prokaryotes), but no determinate lineages among the collectives (no analog of cell lineages in prokaryotes)" (Booth 2014, 668). Consequently, the hologenome is not apt for selection. 5 As Douglas and Werren (2015) put the point,

A host plus its microbiome is more effectively viewed as an ecological community of organisms that encompasses a broad range of interactions (parasitic to mutualistic), patterns of transmission (horizontal to vertical), and levels of fidelity among partners. The hologenome requires high partner fidelity if it is to evolve as a unit. However, even when this is achieved by particular host-microbe pairs, it is unlikely to hold for the entire host microbiome, and therefore the community is unlikely to evolve as a hologenome. (1)

Douglas and Werren's skepticism about the conceptual utility of the holobiont concept is predicated on their claim that holobionts are not selectable entities. In other words, these authors implicitly deny that holobionts are biological individuals. Advocates of the holobiont concept have resisted this criticism. Doolittle and Booth (2017) summarize their response as follows:

Backers of more inclusive holobiont/hologenome thinking ... argue that the idea of holobionts as units of selection was never the sole focus of their theoretical explorations [and] holobionts and hologenomes" are "not restricted to one special process but constitute a wider vocabulary and framework for host biology in light of the microbiome" (Theis et al. 2016, 1). This framework allows that "hologenomic variation may arise not only by mutation and recombination in the host and microbiome but also by acquisition of new microbial strains from the environment, a change in microbial abundance, and horizontal transfer among microbes" (Theis et al. 2016, 2). Such variability notwithstanding, these authors insist that "one can look at holobionts and hologenomes as incontrovertible realities of nature." (Theis et al. 2016, 2)

To this, Doolittle and Booth respond that "it is arguably the case that forgoing any requirement for holobionts to be units of selection and/or to reproduce collectively, is, for all intents and purposes, throwing out the baby with the bathwater" (10).

Doolittle and Booth have good intentions; they want to salvage the holobiont concept. But their preferred avenue for doing so is to argue that, despite appearances, holobionts are biological

\footnotetext{
${ }^{5}$ But see the response by Doolittle and Booth (2017) who argue that it is the functions performed by microbiotic symbionts are apt for selection.
} 
individuals, by suggesting that the functions performed by microbiotic symbionts are apt for selection.

This approach is too restrictive. Indeed, I agree with Theis that "one can look at holobionts and hologenomes as incontrovertible realities of nature" (Theis et al. 2016, 2), the sort of realities that need not be biological individuals. Douglas and Werren are committed to the view that for a biological system to count as an entity it must be a biological individual, and for it to be a biological individual it must be a unit of selection. But on my account, biological systems need not be individuals in order to be biological entities. That is, systems can be entities by being individuals, but they can also be entities by being organisms.

The analysis of organismality that I have presented in this paper shows that one can grant that holobionts are not biological individuals while also granting that they-as functionally differentiated and integrated persisters - are organisms. The claim that holobionts are "incontrovertible realities of nature" that are not units of selection is just the claim that they are organisms but not biological individuals, and if we grant that organismality is a scientifically respectable biological rank that is orthogonal to individuality this does not amount to throwing the baby out with the bathwater. Furthermore, in light of the constitutively embedded character of organisms, which implies that there is no precise line of demarcation between organisms and environments, viewing holobionts as ecological communities of organisms does not rule out viewing them as organisms. Recognizing that organisms are not free-floating and accepting the view that they inevitably persist in complex, efficacious, consequential associations, I think, ought to be reason for not theorizing about them as individuals separate and apart from other systems. Indeed, as I hope has become evident, this work is an explicit repudiation of the possibility of so treating biological systems.

Given that paradigmatic organisms are in fact cluster systems, one might wonder whether the holobiont idea, as conventionally understood, may be overly restrictive. Limiting holobiont systems to host-microbiome relations seems arbitrary. Having accepted that paradigmatic organisms are cluster systems, why not entertain the possibility that they are also parts of other kinds of clusters or networks, in which they are constitutively embedded, that can also be understood as organisms? I have in mind here the idea of the extended bolobiont. Consider the mutualistic relationship between, say, oxpecker birds, which pick blood-filled ticks from large ungulates and eat them, and the ungulates that they (the birds) benefit, and that are benefitted by them. The birds contribute to the persistence of the mammals, ${ }^{6}$ and the mammals contribute to the persistence of the birds, and both play a role in the persistence of various microbionts, and vice versa, and all of these organisms are nodes in a complex web of dependencies-of constitutive embeddedness-extending far beyond these animals' bodies.

To be sure, the oxpecker-ungulate relationship is less integrated than the relationship between gut bacteria and Homo sapiens, or the members of a honey bee system, or the zooids constituting a Portuguese Man O' War. But why should we think that there is some determinate cut-off point between those systems that count as organisms and those that do not?

I have argued that organisms are biological systems whose persistence is underpinned by a differentiated and integrated phenotype. Both differentiation and integration are continuous, incremental properties. Perhaps, then, it makes sense to regard relatively stable associations such as the ungulate-cowbird-tick system as organisms, but less of organisms, than those that display a greater degree of stability, differentiation, and integration. Perhaps organismality is vague and the dividing line between organism and non-organism is more a function of the parameters of one's explanatory project than it is a fact about the structure of the biological world.

${ }^{6}$ This is somewhat controversial, as the relationship may be parasitic rather than mutualistic (Weeks 2000), but even in this case the mammals contribute to the persistence conditions of the birds. 
There are more questions than answers here, but whatever answers one ultimately adopts, attending to persistence, development, and constitutive embeddedness opens up novel avenues for thinking about what it is that organisms are.

\section{Acknowledgments}

Thank you, thoughtful anonymous reviewers, for helpful suggestions which made the paper much better. David Livingstone Smith, I appreciate your support and suggestions. Thanks to UNH Center for Humanities for a grant that allowed me the time to think and write.

\section{Literature cited}

Benson, Keith R. 1989. "Biology's 'Phoenix': Historical Perspectives on the Importance of the Organism.” American Zoologist 29 (3): 1067-1074.

Booth, Austin. 2014. "Symbiosis, Selection and Individuality." Biology and Philosophy 29 (5): 657-673.

Bordenstein, Seth R., and Kevin R. Theis. 2015. "Host Biology in Light of the Microbiome: Ten Principles of Holobionts and Hologenomes." PLOS Biology https://doi.org/10.1371/journal.pbio. 1002226.

Bouchard, Frédéric, and Phillppe Huneman. 2013. From Groups to Individuals: Evolution and Emerging Individuality. Cambridge, MA: MIT Press.

Clarke, Ellen, and Samir Okasha. 2013. "Species and Organisms: What Are the Problems?" In From Groups to Individuals: Evolution and Emerging Individuality, edited by Frédéric Bouchard and Philippe Huneman, 55-76. Cambridge, MA: MIT Press.

Dawkins, Richard. 2002. The Extended Phenotype. Oxford: Oxford University Press.

Demarest, Boris, and Charles T. Wolfe. 2017. "The Organism as Reality or as Fiction: Buffon and Beyond." History and Philosophy of the Life Sciences 39 (1): 2. https://doi.org/10.1007/ s40656-016-0128-8.

Dennett, Daniel C. 2017. "Darwin and the Overdue Demise of Essentialism." In How Biology Shapes Philosophy: New Foundations for Naturalism, edited by David Livingstone Smith, 9-22. Cambridge: Cambridge University Press.

Doolittle, W. Ford, and Austin Booth. 2017. "It's the Song not the Singer: an Exploration of Holobiosis and Evolutionary Theory." Biology and Philosophy 32 (1): 5-24.

Douglas, Angela R., and John H. Werren. 2015. "Holes in the Hologenome: Why Host-Microbe Symbioses are not Holobionts.” mBio 7 (2): e02099-15.

Dunn, Casey. W., and Günter P. Wagner. 2006. “The Evolution of Colony-level Development in the Siphonophora (Cnidaria:Hydrozoa).” Development Genes and Evolution 216: 743-754

Gardner, Andy, and Alan Grafen. 2009. "Capturing the Superorganism: a Formal Theory of Group Adaptation.” Journal of Evolutionary Biology 22 (4): 659-671.

Godfrey-Smith, Peter. 2013. “Darwinian Individuals.” In From Groups to Individuals: Evolution and Emerging Individuality, edited by Frédéric Bouchard and Philippe Huneman, 17-36. Cambridge, MA: MIT Press.

Gillooly, James F., Chen Hou, and Michael Kaspari. 2010. "Eusocial Insects as Superorganisms: Insights from Metabolic Theory." Communicative and Integrative Biology 3 (4): 260-262.

Haber, Matthew. 2013. “Colonies are Individuals: Revisiting the Superorganism Revival.” In From Groups to Individuals: Evolution and Emerging Individuality, edited by Frédéric Bouchard and 
Philippe Huneman, 195-218. Cambridge, MA: MIT Press.

Hamilton, Andrew, Nathan R. Smith, and Matthew. H. Haber. 2009. "Social Insects and the Individuality Thesis: Cohesion and the Colony as a Selectable Individual." In Organization of Insect Societies: From Genome to Sociocomplexity, edited by Jürgen Gadau and Jennifer Fewell, 572-589. Cambridge, MA: Harvard University Press.

Hölldobler, Bert, and Edward O. Wilson. 2009. The Superorganism: The Beauty, Elegance, and Strangeness of Insect Societies. New York: W. W. Norton.

Huneman, Philippe, and Charles T. Wolfe. 2010. "The Concept of Organism: Historical, Philosophical, Scientific Perspectives." History and Philosophy of the Life Sciences 32: 147-154.

Jablonka, Eva, and Marion J. Lamb. 2005. Evolution in Four Dimensions: Genetic, Epigenetic, Behavioral, and Symbolic Variation in the History of Life. Cambridge, MA: MIT Press.

Kitcher, Phillip S. 2001. "Batting the Undead: How (and How Not) to Resist Genetic Determinism." In Thinking About Evolution: Historical, Philosophical, and Political Perspectives, edited by Rama S. Singh, Costas B. Krimbas, Diane B. Paul, and John Beatty, 396-414. Cambridge: Cambridge University Press.

Laubichler, Manfred D. 2010. "Evolutionary Developmental Biology Offers a Significant Challenge to the Neo-Darwinian Paradigm.” In Contemporary Debates in Philosophy of Biology, edited by Francisco L. Ayala and Robert Arp, 199-212. Malden, MA: Wiley-Blackwell.

Laubichler, Manfred D. 2000. "Symposium 'The Organism in Philosophical Focus'-An Introduction.” Philosophy of Science 67: S256-S259.

Lewontin, Richard. C. 1991. Biology as Ideology. New York: Harper.

Leitão-Gonçalves, Ricardo, Zita Carvalho-Santos, Ana P. Francisco, Gabriela T. Fioreze, Margarida Anjos, Célia Baltazar, Ana P. Elias, Pavel M. Itskov, Matthew D. W. Piper, and Carlo Ribeiro. 2017. "Commensal Bacteria and Essential Amino Acids Control Food Choice Behavior and Reproduction.” PLOS Biology 15 (4): e2000862.

Margulis, Lynn. 1991. “Symbiogenesis and Symbionticism.” In Symbiosis as a Source of Evolutionary Innovation: Speciation and Morphogenesis, edited by Lynn Margulis and René Fester, 1-14. Cambridge, MA: MIT Press.

Martens, Johannes. 2010. “Organisms in Evolution." History and Philosophy of the Life Sciences 32 (23): 373-400.

Matthen, Mohan, and André Ariew. 2002. “Two Ways of Thinking About Fitness and Natural Selection." Journal of Philosophy 99 (2): 55-83.

Moritz, Robin F. A., and Stefan Fuchs. 1998. "Organization of Honeybee Colonies: Characteristics and Consequences of a Superorganism Concept.” Apidologie 29: 7-21.

Okasha, Samir. 2011. "Biological Ontology and Hierarchical Organization: A Defense of Rank Freedom." In Major Transitions in Evolution Revisited, edited by Brett Calcott and Kim Sterelny, 5363. Cambridge, MA: MIT Press.

Oyama, Susan, Russell D. Gray, and Paul E. Griffiths. 2003. Cycles of Contingency: Dervelopmental Systems and Evolution. New York: Bradford.

Page, Paul, Zheguang Lin, Ninat Buawangpong, Huoqing Zheng, Fuliang Hu, Peter Neumann, Panuwan Chantawannakul, and Vincent Dietemann. 2016. "Social Apoptosis in Honey Bee Superorganisms.” Scientific Reports 6: 27210. https://doi.org/10.1038/srep27210.

Pechenik, Jan A. 2005. Biology of Invertebrates. New York: McGraw Hill.

Pepper, John W., and Matthew D. Herron. 2008. “Does Biology Need an Organism Concept?” Biological Reviews 83 (4): 621-627. 
Pradeu, Thomas. 2010. "What is an Organism? an Immunological Answer." History and Philosophical of the Life Sciences 32 (2-3): 247-267.

Purcell, Jennifer E. 1984. "Predation on Fish Larvae by Physalia physalis, the Portuguese Man of War." Marine Ecology Progress Series 19:189-191.

Queller, David. C., and Joan E. Strassmann. 2009. "Beyond Society: the Evolution of Organismality.” Philosophical Transactions of the Royal Society B, Biological Sciences. 364: 3143-3155.

Sterelny, Kim, and Paul Griffiths. 1999. Sex and Death: An Introduction to Philosophy of Biology. Chicago: University of Chicago Press.

Torres, José-Leonel, and Lynn Trainor. 2008. "On Organism: Environment Buffers and Their Ecological Significance.” Biology and Philosophy 23 (3): 403-416.

Theis, Kevin R., Nolwenn M. Dheilly, Jonathan L. Klassen, Robert M. Brucker, John F. Baines, Thomas C. G. Bosch, John F. Cryan, Scott F. Gilbert, Charles J. Goodnight, Elisabeth A. Lloyd, Jan Sapp, Philippe Vandenkoornhuyse, Ilana Zilber-Rosenberg, Eugene Rosenberg, and Seth R. Bordenstein. 2016. "Getting the Hologenome Concept Right: An Eco-Evolutionary Framework for Hosts and Their Microbiomes." mSystems 1 (2):e00028-16.

Turner, J. Scott. 2002. The Extended Organism: The Physiology of Animal-Built Structures. Cambridge, MA: Harvard University Press.

Santelices, Bernabé. 1999. "How Many Kinds of Individual are There?" Trends in Ecology and Evolution 14 (4): 152-155.

Seeley, Thomas D. 1985. Honeybee Ecology: A Study of Adaptation in Social Life. Princeton: Princeton University Press.

Stabentheiner, Anton, Helmut Kovac, and Robert Brodschneider. 2010. "Honeybee Colony Thermoregulation-Regulatory Mechanisms and Contribution of Individuals in Dependence on Age, Location and Thermal Stress." PLOS ONE 5 (1): e8967. https://doi.org/10.1371/journal. pone.0008967.

Stearns, Stephen C. 1983. "The Evolution of Life-history Traits in Mosquitofish Since Their Introduction to Hawaii in 1905: Rates of Evolution, Heritabilities, and Developmental Plasticity." American Zoologist 23 (1): 65-75.

Sultan, Sonia. E. 1992. "Phenotypic Plasticity and the Neo-Darwinian Legacy." Evolutionary Trends in Plants 6 (2): 61-71.

Walsh, Denis M. 2012. "Situated Adaptationism.” In The Environment: Philosophy, Science, and Ethics, edited by Willian P. Kabasenche, Michael O’Rourke, and Matthew H. Slater, 89-116. Cambridge, MA: MIT Press.

Walsh, Denis M. 2014. “The Affordance Landscape: the Spatial Metaphors of Evolution.” In Entangled Life: Organism and Environment in the Biological and Social Sciences, edited by Gillian Barker, Eric Desjardins, and Trevor Pearce, 213-236. New York: Springer.

Weeks, Paul. 2000. "Red-billed Oxpeckers: Vampires or Tickbirds?” Behavioral Ecology 11 (2): 154160.

Tautz, Jürgen. 2008. The Buzz about Bees: Biology of a Superorganism. New York: Springer.

West-Eberhard, Mary Jane. 1989. "Phenotypic Plasticity and the Origins of Diversity." Annual Review of Ecology and Systematics 20: 249-278.

West-Eberhard, Mary Jane. 2003. Developmental Plasticity and Evolution. New York, NY: Oxford University Press.

West-Eberhard, Mary Jane. 2005. "Developmental Plasticity and the Origin of Species Differences." Proceedings of the National Academy of Sciences 102 (1): 6543-6549.

๑ OPEN ACCESS - PTPBIO.ORG 
Westneat, David E., and Charles W. Fox. 2010. Evolutionary Behavioral Ecology. New York, NY: Oxford University Press.

Wilson, David Sloan, and Elliott Sober. 1989. "Reviving the Superorganism.” Journal of Theoretical Biology 136 (3): 337-356.

Wilson, Edward O. 1975. Sociobiology: The New Synthesis. Cambridge, MA: Harvard University Press.

Wilson, Jack A. 1999. Biological Individuality: The Identity and Persistence of Living Entities. Cambridge: Cambridge University Press.

Wilson, Jack A. 2000. "Ontological Butchery: Organism Concepts and Biological Generalizations.” Philosophy of Science 67: S301-S311.

(C) 2017 Author(s)

This is an open-access article distributed under the terms of the Creative Commons AttributionNonCommercial-NoDerivatives 4.0 International license, which permits anyone to download, copy, distribute, or display the full text without asking for permission, provided that the creator(s) are given full credit, no derivative works are created, and the work is not used for commercial purposes.

ISSN 2475-3025 